\title{
Cost impression on Human Resource Accounting
}

\author{
S. Revathy, S. Pragadeeswaran
}

\begin{abstract}
The main resource in every organization is "Human resource". They are asset for the organization and they develop organization's productivity and profitability. Human resource is to direct and control the production and profit in the organization. Employees are considered as main factors but they do not belong in the balance sheet as an asset.Many organization do not use any accurate cost model to measure employees cost and value.The employees value does not considered in the organisation. We can measure that value of an employeein different ways, are1.standard cost2.replacement cost3.opportunity cost4.economic value.These cost methods are involved capitalisation of actual cost on recruitment, selection, learning and development, hiring, etc., of personnel in the organization. This research article is focused on theoretical conceptual paper of HRA, it helps the organisation to make important decision making by the help of Human Resource Cost Accounting method.
\end{abstract}

Index Terms: Human Resource, Human, Cost, Value, Human Resource Cost Accounting Method.

\section{INTRODUCTION}

Nowadays each organization ought to reduce their expertise's costs and they ought to exhibit their esteem which call Human Resource Cost or Human Resource Accounting.

In some organization different methods are followed, few of them are Human Resource Cost Accounting Method (HRCAM) and Traditional Accounting Approach (TAA). HRCAM, propose that human asset consumption is treated as an advantage in the organization's monetary record. In TAA, the HR consumption will be treated as use in their wage and they decrease in benefit and misfortune account.

HRA was started in USA by the name money related announcing models however later, it is known as sound accounting standards (GAAP) - it measure the organization resources and they pursue conventional cost approach.

The beginning period of HRA was completed by "University of Michigan" the therapist researcher Mr.Renis Likert originator of "University of Michigan Foundation of Social Research". In (1961, 1967 of Likert) the study was about management style and management theory with faculty R.LeeBrummet and Ph.D Research Scholar William C.Pyle and Eric Flamhaltz. They workedthe projects together and developed the methods, concepts of accounting in Human Resource. And HRA name was introduced in their paper presentation Human Resource Measurement.

S. Revathy, Department of Business Administration, Annamalai University, Chidambaram, Tamil Nadu, India.

Dr. S. Pragadeeswaran, Department of Business Administration, Annamalai University, Chidambaram, Tamil Nadu, India. they given in the organization. To gauge those expenses is we

Revised Manuscript Received on July 05, 2019.

In India most of the companies are using Lev \& Schwartz model to evaluate HRA. they identify that HRA is essential to make decision making for company's objective and to improve returnof the organization.

Flamhaltz (1999) Human Resource cost is to measure and capitalized employees cost in the company balancesheet which is based on historical cost, replacement cost, opportunity cost, economic value cost.

\section{Cost Accounting Ideas}

Accounting utilizes the idea of cost in an assortment of ways. Those ways are verifiable cost, procurement cost, expense cost, substitution cost, and current cost, coordinate furthermore, circuitous cost, standard cost, incremental cost, sunk cost, settled and variable expense, minor expenses, and opportunity cost, to refer to sum of the more typical courses in which the term cost is utilized.

Cost: Adroitly, all expenses have "cost" and "resource" parts. Routinely characterized, a cost is the segment of a cost that has been devoured amid the current bookkeeping period. An advantage is the segment of a cost that is required to give benefits amid future bookkeeping periods. A crucial bookkeeping issue is, obviously, estimating the cost and resource segments of expenses.

\section{Ideas of Human Asset Cost}

The thought of "human asset cost" is gotten from the general idea of expense. Human asset costs will be costs caused to secure or supplant individuals. Like other costs, they have cost and resource segments; they might be made out of expense what's more, open door expenses; and they may have both immediate and aberrant cost components. In expansion, it is conceivable to represent standard and in addition genuine human asset costs. At long last, the traditional bookkeeping ideas of obtaining and substitution cost likewise have partners in human asset bookkeeping.

Unique Cost of Human Assets: The first expense of HR alludes to the forfeit that was brought about to get and create individuals. This idea is indistinguishable to the idea of unique expense for different resources for instance, the first cost of plant and gear is the cost brought about to obtain these assets.

The first expense of HR ordinarily incorporates expenses of selection, orientation, hiring, recruitment, and on-the-job training.

\section{Authentic cost of human Asset}

Acquisition cost: These prices are incurred in bringing new control personnel or everyday employees to the institution. This class consists of placement prices, shifting

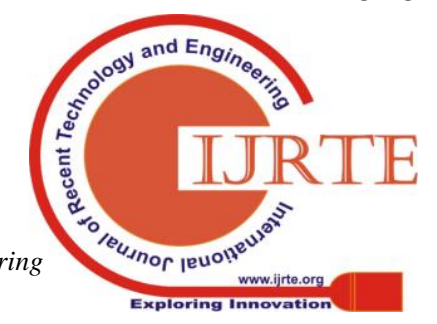


charges, bodily exam, allocation of personnel, and acquiring department time in setting a person on the payroll and situating him with the necessary system to carry out this process

Learning costs: allude to the forfeit that must be caused to prepare a man and convey it to the level of execution typically expected of a person in a given position.

\section{LITERATURE REVIEW}

Evi Rahmawati (JAN 2006) opinions the issues on evaluation to look at find that historical price remains are relevant in choice making. Empirical studies show evidence on assisting ancient fee account and its criticize the traditional ancient cost and it fully based on monetary statement. Due to financial condition, cost in inflation, environment hike, charge actions and regulators statement are raised in historical cost. This review is about accounting on historical cost. In the course of the most recent decade, the power informative for purchasers, this recommends that its points of interest exceed its cost. Barth et.al. (1996) offer proof in increment info on contemporary value for positive belongings and debt. She said that, there are weakness (in opposition to) HCA and it will give big benefits.

Yuriy V Kozyr (NOV28, 2016) According to the mounted valuation exercise, when valuing groups (organizations, commercial enterprise and retail asset) pay \& commercial center strategies are commonly completed. Cost approach is restrained and its typically employ whilst value small organization (people have better historic records) protecting group. Author shows value method, expand outlook of earnings technique factors. Author gives depiction of the valuation system, essayist call Resources Substitution Cost Strategy (ARCM). According to replacement concept, as per which the financial specialist will now not pay more for a benefit than the maximum important to make an advantage of same application, be it with the guide of obtaining or creation. This approach is based at the price technique and carries a few factors of the earnings technique, which permits that strength and weakness of each method. Writer's view, this may be categorized as hybrid, much like the EVA and EBO valuation processes.

NelaSteliac (july2,2015) the study attempted to make a quick historic presentation, of the advent, evolution and the applicability of the opportunity value idea inside the low-cost questioning sample in popular and specially for the accounting. The complexity of this idea permits to be seemed from the accounting angle, truth that results in the concept of the accounting size of the possibility cost. The examples presented in the content of the study pursuits to point out the need and the significance of the possibility fees with the intention to set up the accounting profit for the destiny durations of time starting from the accounting statistics. It is confirmed that the dimensions of the accounting earnings, the rent ability of the work production can be and is stimulated by using the opportunity charges for some reasons the cost is ignored by the accountants.

Salaga Jakub (2015) the study affirm that fee-primarily based idea of measuring business overall performance has its theoretical basis in financial profit. The concept of financial profit is based totally at the life of possibility prices which can be very widely recognized in the financial theory. The creator manages size of the money related profit by the Monetary Esteem Included pointer (EVA indicator). It points out, that after thinking about the monetary income and its dimension one should first distinguish the theoretical foundation of the idea, types of application and opportunities of software in practice. The accumulated records and the transformation of the records got through from the accounting into the preferred styles, individually to the Economic Value Added method. Primary statistics as well as secondary information had been used for the motive, along with numerous strategies inclusive of analysis, synthesis, deduction, etc.

\section{Objectiveon Human Resource Accounting}

The two main objectives of HRA are

- To cost of human asset

- To value of human asset

\section{Cost of Human Asset in HRA}

Four methods, to measure human asset in cost method of HRA. They are

- Historical Cost Method

- Replacement Cost Method

- Opportunity Cost Method

- Economic value method

\section{Historical Cost Method}

This accounting method of human sources turned into first initiated with the aid of Rinses Likert at R.G.Bary Corporation in Ohio Columbia (USA) in 1967. Capitalisation on real value accure on enrolment, choosing, employ, growing the employee sources in the enterprise. The cost of employees in the agency represent that price of the human assets. This cost is defrayal over the foreseen time of administration of individual staff. The unexpired expense is considered to be the funding in human assets. If worker leaves the corporation because of renunciation, passing, expulsion etc., whole amount are not written off to the employee it is charged to the current sales or current revenue.

The aggregate expense of the venture incorporates those quantifiable consumptions related with enrolment, choice, contracting, preparing, situation, acquaintance and advancement. This technique just underwrites human asset costs and does not look to esteem individuals. It is like the approach pursued while esteeming settled resources and discounting their expense over their helpful life. The expense is promoted, not being charged against current wage and a conceded tax assessment charge is made on the notional increment in benefit. This strategy is straightforward and meets the trial of customary standard of accounting i.e. coordinating of expense with income.

\section{Replacement Cost Method}

G. Flamholtz based on thought of elective esteem forewarned with the guide of Rensis Likert.

Replacement cost alludes to the forfeit that would need to be brought about to supplant assets directly possessed or utilized. This strategy depends on current esteem or substitution cost. Under this framework, an association esteems a representative at the assessed expense of supplanting with another worker of identical capacity. The utilization of such a 
technique, be that as it may, is made troublesome by the issues of characterizing and estimating replacement costs. In the setting of HR, it alludes to the cost that would need to be brought about to supplant HR by and by utilized. Flamholtz has alluded to two distinct ideas of replacement cost viz., person replacement cost and positional replacement cost.

\section{Opportunity Cost Method}

Opportunity cost method of HRA looks to gauge the estimation of HR on the premise of normal idea of chance expense. This cost method was proposed by Hekimian and It endeavours to gauge the estimation of HR by setting up an inside work showcase in an association through the procedure of aggressive offering. Under this model all chiefs of benefit focuses are urged to offer for any rare worker they need. This is largely synthetic method regarding the idea of the competitive bidding process. Under this framework, profit centre administrators are urged to offer for rare representatives, the effective offer being incorporated into the association's human speculation counts.

Worker capacities are identified with benefit age, and may prompt a more proficient assignment of HR. The worker is apportioned to the most astounding bidder among the divisional supervisors and the offer cost is incorporated into that division's speculation base.

\section{Economic Value Method}

Financial esteem based methodology will break down, the future estimation of the representatives just dependent on their current execution and administration in the organization. The two models of economic value method are Financial Measures (Monetary Measure) and Non-Money related Measures (Non- Monetary Measure).

\section{Monetary Measure}

Many specialists given numerous models in HRA to investigate the estimation of the workers (or) individual in the association. The models are Flamholtz's model - deciding the Individual Incentive in the association, Flamholtz's stochastic prizes valuation Show and The Lev and Schwartz display. As indicated by Flamholtz's model, (on deciding the individual estimation of the worker) the estimation of an individual is fundamentally founded on the present administration that he renders to the organization. In view of his/her present administration their future administration will be resolved in their organization. There are two measurements in this model.

- Expected restrictive esteem - It implies the Profitability, execution, advancements, and exchange to the worker in the association.

- Expected feasible esteem - Is to know the worker efficiency benefit period in the association.

Flamholtz's stochastic prizes valuation display depicts the estimation of individual contingent esteem and the expected acknowledged estimation of a worker in the association. The Lev and Schwartz demonstrate as per this model, the estimation of a person who is 'a' year old, is the present estimation of his future income from business. It very well may be computed by utilizing the recipe underneath:

$\mathrm{E}(\mathrm{Va})=\mathrm{I}(\mathrm{t}) /(1+\mathrm{R}) \mathrm{t}-\mathrm{a}$

Where, Jones to conquer the confinements of substitution cost show.

$\mathrm{E}(\mathrm{Va})=$ expected estimation of a 'a' year old person's human capital

$\mathrm{t}=$ the person's retirement age

$\mathrm{R}=$ markdown rate

$\mathrm{I}=$ expected profit of the person in period I

\section{Non - Monetary Measure}

The Non-Fiscal measures in human asset accounting portray the financial estimation of the scholarly resources, however not in the term of money related. The Non-Fiscal measures are,

1. Aptitudes of the human asset in the association.

2. Singular execution - Assessing the individual execution of the human asset and rating there execution level in the association.

3. Decide the activity fulfilment level of the human asset in the association.

\section{RESEARCH METHODOLOGY}

Research methodology is a techniques utilized for tackling the issue deliberately. It is the best approach to comprehend the procedure of research towards the arrangement on research issue. There is a different intelligent route for the analyst to receive the strategy. The exploration configuration utilized in this examination is to secure the data dependent on the structure and to take care of the exploration issue. An examination configuration is there characterized as" An arrangement, structure and procedure of examination imagined in order to get answers to inquire about inquiry and control difference.

The example populace of this examination is taken from the mastery see point on human asset accounting in the organization. Testing might be characterized as the determination of some piece of a total (or) totality based on which a judgment (or) deduction about the total (or) totality is made.

Significantly, this exploration has been focused on the financially savvy measurements on human asset bookkeeping through the optional information by means of. Accessible books, diaries, articles, magazines, daily paper and furthermore applicable sites.

\section{CONCLUSION}

The employees are the best resources of an organization. The achievement and disappointment of the organization is only relies on the execution and administration nature of a employees. But this profitable human resource (or) scholarly resource was not follow in the traditional accounting strategy. HRA assist organization with monitoring the utilization of mortal asset and increment the mindfulness on human incentive in the organization. Its empower high-lasting chance for arranging more planning and budgeting in the organization. The HRA execution enhances administrative choices like cutbacks, better execution assessment proportions of the firm and furthermore goes about as a guide amid purchasing, offering and merger exchanges in the organization.

Published By: 


\section{REFERENCES}

1. EviRahmawati, Januari 2006, "Support and Against Historical Cost Accounting: Is it Value Relevance for Decision Making?" JurnalAkuntansi dan Investasi Vol. 7.

2. Yuriy V Kozyr , November 28, 2016, "Business Valuation Based on Assets Replacement Cost" at Arabian Journal of Business and Management Review.

3. NelaŞteliac, july 2015, "A Historical View Over the Opportunity Cost - Accounting Dimension” At Istanbul, Turkey, Volume: II.

4. Salaga Jakub, 26 (2015), "Economic Value Added as a measurement tool of financial Performance" Procedia Economics and Finance.

5. M. Rajalakshmi, May 2015, "Cost Effective Metrics through HRA" Mediterranean Journal of Social Sciences, MCSER Publishing, Rome-Italy, Vol 6, No 3.

6. GürhanUysal, Sep - Oct. 2016, "Human Resource Accounting: Costs and Benefits Analysis" Management Studies, Vol. 4, No. 5.

7. Dr.S.Rajendran, Aug 2015, "Human Resource Accounting" The International Journal of Business \& Management, Vol. 3 Issue 8.

8. IfathShaheen, Jan 2016 " A Study on HR Accounting Practices in Selected Companies" International Journal of Innovative Research \& Development, Vol. 5 issue 2.

9. Dr.SamirMazidbhal Vohra, Dec 2015 "Evaluation of Human Resource Accounting Practices in Infosys" IJSR-International Journal of Scientific Research, Vol .1, issue 12.

10. Dr.Kalpana.R, July 2014 "Trends And Issues of Human Resource Accounting” Research Gate. 